\title{
Design of a Three-Dimensional Hypersonic Inward-Turning Inlet with Tri-Ducts for Combined Cycle Engines
}

\author{
Chengxiang Zhu $\left(\mathbb{D}\right.$, Xu Zhang $\mathbb{D}^{\mathbb{D}}$, Fan Kong $\mathbb{D}^{D}$, and Yancheng You $\mathbb{1}$ \\ School of Aerospace Engineering, Xiamen University, Xiamen 361005, China \\ Correspondence should be addressed to Yancheng You; yancheng.you@xmu.edu.cn
}

Received 25 May 2018; Revised 30 July 2018; Accepted 26 August 2018; Published 27 November 2018

Academic Editor: Jose Carlos Páscoa

Copyright (c) 2018 Chengxiang Zhu et al. This is an open access article distributed under the Creative Commons Attribution License, which permits unrestricted use, distribution, and reproduction in any medium, provided the original work is properly cited.

\begin{abstract}
The operation of a propulsion system in terms of horizontal takeoff/landing and full-speed range serves as one of the main difficulties for hypersonic travelling. In the present work, a three-dimensional inward-turning inlet with tri-ducts for combined cycle engines is designed for the operation of three different modes controlled by a single rotational flap on the compression side, which efficiently simplifies the inlet structure and the flap control mechanism. At high flight speed between Mach 4 and 6, the pure scramjet mode is switched on, whereas both the ejector and the scramjet paths are open for a moderate Mach number between 2 and 4 with a larger throat area guaranteeing the inlet startability. In the low flight speed range with Mach number below 2, the additional turbojet path will be turned on to supply air for the turbine engine, whereas the other two paths remain open for spillage. Numerical simulations under different operation modes have proven the feasibility and good performance of the designed inlet, e.g., a nearly full mass flow ratio and a total pressure recovery around 0.5 can be achieved at the cruise speed. Meanwhile, the inlet works properly at low flight speeds which overcomes the typical starting problem of similar inlet designs. In the near future, wind tunnel experiments will be carried out to validate our inlet design and its performance.
\end{abstract}

\section{Introduction}

For centuries, people have dedicated to achieve higher and higher flight speeds. Imagining a flight trip from Shanghai to New York within only two hours is incredibly promoting. Recently, hypersonic travelling is getting intensive attention from both commercial and scientific communities. The difficulty however lies mostly on the propulsion system when considering its requirement of both horizontal takeoff/landing and full-speed range operation. In this case, only combined cycle engines can satisfy the rigorous expectation since any single engine faces deficiency, e.g., turbojet engine operates up to Mach 3; ramjet engine cannot generate efficient compression inside the inlet below Mach 3; the specific impulse of ejector engine is relatively low due to its selfloading oxidant. In recent years, a number of concepts of combined cycle engine have been raised by various organizations, which in most case are national institutes. For example, Long-Term Advanced Propulsion Concepts and
Technologies (LAPCAT) in Europe aimed at developing a hypersonic transport aircraft with the Reaction Engines Ltd. Scimitar engine which was based on the combined concept of precooling turbojet engine and ramjet technology $[1,2]$. Japan Aerospace Exploration Agency (JAXA) has started the research of hypersonic combined cycle engine since 1990s and claims to develop a demonstration prototype of S-engine before 2025, which will be installed on a Mach 5 hypersonic transport airplane [3]. In USA, Air Force Research Laboratory (AFRL) and National Aeronautics and Space Administration (NASA) are continuously supporting a combined cycle engine project for the purpose of developing a "trijet" engine which has triple suite of propulsion engines (turbojet, ejector ramjet, and dual-mode ramjet) $[4,5]$. Beijing Power Machinery Research Institute raises a turbo-aided rocket-augmented ramjet combined cycle engine (TRRE), which consists of a turbine path and a rocket/ramjet path $[6,7]$. A two-dimensional dual-duct over/under variable geometry inlet is selected for TRRE. In order to meet the 
demand of wide working range of the engine, the TRRE inlet shoulder, the compression ramp, and the splitter are all rotatable, which makes the mechanical control and operation feasibility a big challenge. Therefore, we are thinking of developing a three-dimensional inward-turning inlet with only a single rotational flap on the compression side for combined cycle engines. In the present work, details about the inlet design methodology and numerical analysis of the inlet performance under various operation modes are provided. The content is constructed as follows: first is the theoretical design method of the three-dimensional inward-turning inlet, followed by a description of its working modes. The numerical methods are provided afterwards with a validation case. The performance of the inlet, including its mass flow capturing, startability, losses, and mode transition, is then analyzed, ending with a discussion about its advantages and shortcomings. Finally, a conclusion and outlook are reported.

\section{Design Methodology}

The design of the three-dimensional inward-turning inlet needs to meet the mass requirement within the full speed range of a combined cycle engine. Regarding the full mass flow ratio feature of the inlet at the cruise speed, the inflow capturing area can be established directly. The scramjet flow path can be designed with a preferred intake and exit shape based on the consideration of inlet startability as well as efficient compression. This is an iterative process in consideration of the performance of the inlet, especially its startability which needs to be verified carefully based on viscous simulation, since currently an accurate analytical tool is still lacking. But very soon, an efficient in-house code to evaluate the inlet startability will be addressed by our group based on the Kantrowitz theory and the isentropic limit $[8,9]$. The entrance area of the other two flow paths can also be determined by mass requirements. Emphasis needs to be placed on the internal contraction ratio which accesses the operability of dual-duct mode, and on the expansion passage which restricts the flow stability of tri-duct mode. Details about the design methodology are addressed in the following.

2.1. Basic Flowfield. For hypersonic inward-turning inlet design, a basic flowfield with high performance needs to be identified as the first step. A number of our previous researches have accumulated different design methods as well as optimization for the basic flowfield [10-13]. During our inlet design, the Internal Conical Flow D (ICFD) basic flowfield is adopted in consideration of its better performance and uniformity of the exit flow. Preassigned design parameters of the basic flowfield include the inflow Mach number, the exit Mach number, and the ramp angle. Although the cruise speed for the engine is Mach 6, we choose the inflow Mach number as 5.5 to design the basic flowfield by preconsidering its startability as well as viscous correction. The ramp angle should be a moderate value to avoid high shock loss and friction loss. Currently, an 8degree ramp angle is preferred. The exit Mach number that equals to 2.5 is assigned here to balance the compression ratio and the contraction ratio. With these parameters, the basic
ICFD can be computed with the method of characteristics (MOC) for an accurate solution, as shown in Figure 1(a).

2.2. Scramjet Flow Path. Based on the above basic flowfield, the three-dimensional scramjet flow path can be conducted with the technique of streamline tracing and osculating theory $[14,15]$. But as the first step, the intake and exit shape of the inlet must be specified. In this work, a quasirectangular intake shape, as shown in Figure 1(b), is selected for the inlet in consideration of an easier implementation of the rotational flap on the compression surface which will be convenient for mechanical realization in future experiments. According to the mass requirement of the engine at the cruise speed Mach 6 and cruise altitude $28 \mathrm{~km}$, the projection area of the intake along the streamwise direction can be computed. The exit shape of the inlet is determined as ellipse to weaken significant corner flow from the quasirectangular intake, which is also propitious to the downstream stable combustion. The ratio between the long and short axes of the elliptical exit shape equals to 2.6 in this work, and the total contraction ratio of the scramjet flow path is 5.7. The inlet is designed with a short scramjet isolator, since further elongation of the passage can be accomplished in the design of the downstream straight combustor. Configuration of the scramjet flow path is provided in Figure 1(b) together with the other two flow paths.

2.3. Ejector Flow Path. By rotating the flap around the hinge on the compression surface to the position 2 , the ejector flow path will be fully open. The cross-section of the entrance of the ejector flow path keeps a rectangular shape restricted by the flap sweeping. The entrance area, which determines the rotation angle of the flap, is computed based on the mass requirement of the ejector engine. The ejector flow path of the inlet is designed as a straight tube from the flap end to the exit plane, i.e., the exit has the same rectangular shape without contraction or expansion. Further optimization of the ejector flow path can be modified by a one-dimensional theoretical analysis tool which is under construction by our group currently.

2.4. Turbojet Flow Path. Similar to the ejector flow path, the entrance cross-section of the turbojet flow path must be restricted as a rectangular shape due to requirement of further flap rotation. The exit shape, however, has to be circular to fit the geometrical requirement of the turbine engine. Therefore, a variable cross-section passage from rectangular to circular shape is designed for the turbojet flow path with a weak expansion ratio of 1.25 . Since the turbine engine has been selected in advance (i.e., the exit area of the turbojet flow path is fixed), the entrance area of the turbojet flow path which also indicates the rotation limit of the flap can be computed accordingly. The control equation of the center line of the duct is of crucial importance, which directly determines the flow deflection, the pressure gradient, and also the secondary flow characteristics. In this work, a fourth-order polynomial equation as the following form given by Davic is adopted, where $A, B, C, D$, and $E$ are coefficients, $L_{\mathrm{t}}$ is the length of the turbojet flow path, $Y_{t}$ is the offset between the 


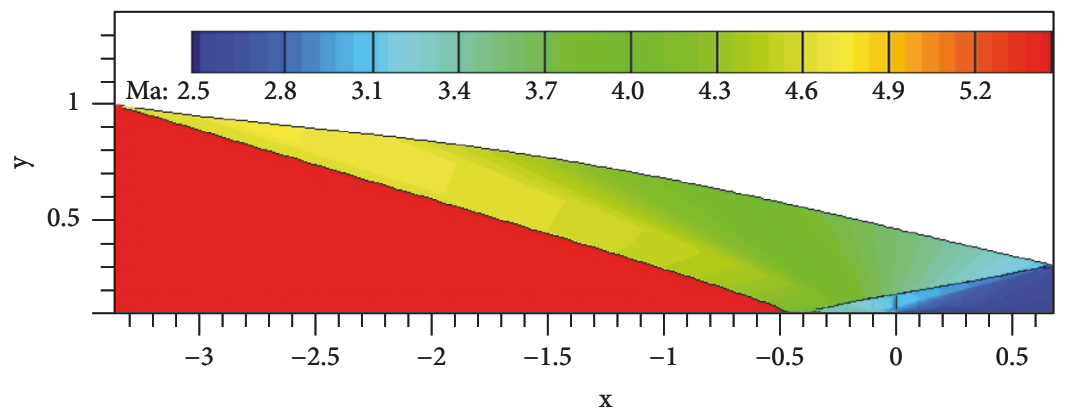

(a)

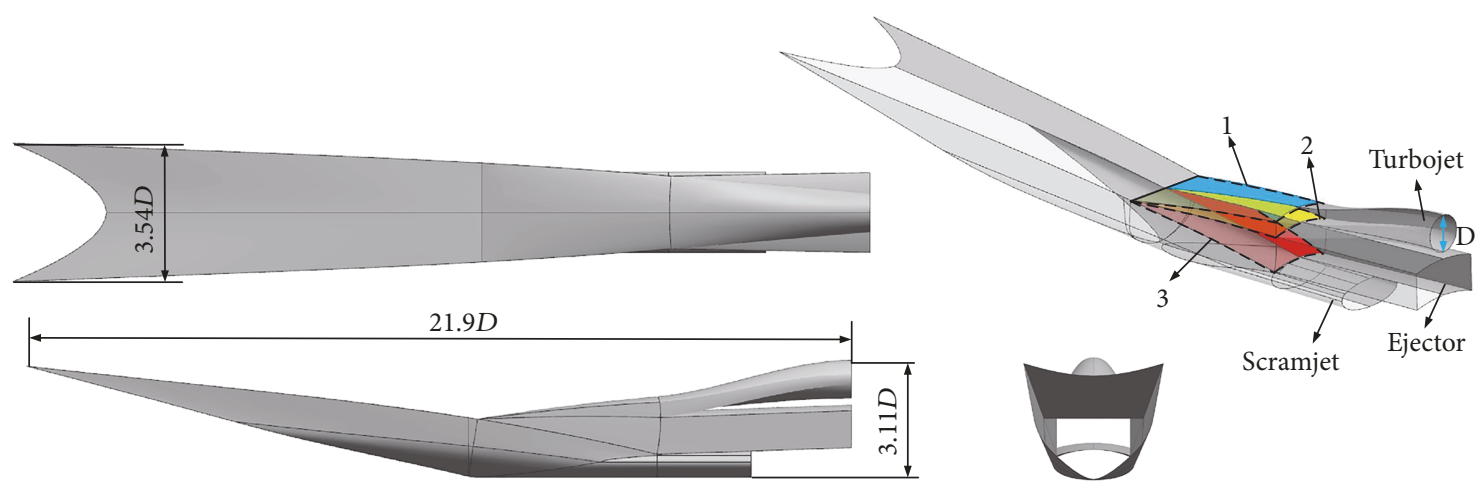

(b)

FIGURE 1: (a) Mach number distribution of the basic ICFD flowfield. (b) Geometry of the tri-duct inward-turning inlet.

starting and the ending points, and $x$ and $y$ are curve coordinates along the two directions $[14,15]$. The five coefficients can be established with boundary restrictions, i.e., three settle points (normally are starting, ending, and middle points) and two slops (at starting and ending points).

$$
\frac{y}{Y_{t}}=A\left(\frac{x}{L_{t}}\right)^{4}+B\left(\frac{x}{L_{t}}\right)^{3}+C\left(\frac{x}{L_{t}}\right)^{2}+D \frac{x}{L_{t}}+E .
$$

2.5. Working Modes. In the present work, the targeted aircraft is a drone where the takeoff weight is of unit ton and the lift/ drag ratio at the cruise speed is about 4.5. The combined cycle engine is designed for the aircraft from horizontal takeoff to hypersonic cruise with three basic working modes: turbojet mode from takeoff to Mach 2, ejector mode from Mach 2 to Mach 4, and scramjet mode from Mach 4 to cruise Mach 6 , i.e., the transfer Mach number between the turbojet mode and the ejector mode is 2, whereas the transfer Mach number between the ejector mode and the scramjet mode is 4 , which also means that the single scramjet flow path must be able to start as low as Mach 4, and the dual ducts (both ejector and scramjet flow paths) must work properly at Mach 2. According to the desired working envelope provided by overall analysis, the flight altitude and the mass requirement of the inlet can be plotted versus flight Mach number in Figure 2.

\section{Numerical Simulation Methodology}

3.1. Numerical Methods. In order to prove the inlet design methodology, simulations were conducted based on the commercial software Ansys Fluent 14.0@. Density-based steady
Reynolds-averaged Navier-Stokes (RANS) equations were solved, in which the two equation $k-w$ shear stress transport (SST) turbulence model is adopted. The flux term is solved with Roe-FDS (Roe flux-difference splitting) scheme. The $1^{\text {st }}$-order upwind scheme is used to discretize the equations spatially to get a stable initial flowfield, based on which the $2^{\text {nd }}$-order upwind scheme is further applied for a refined resolution. The fluid is treated as ideal gas, with a constant specific heat $1006.43 \mathrm{~J} /(\mathrm{kgK})$ and a constant viscosity $1.789 \mathrm{e}-5 \mathrm{~kg} /(\mathrm{ms})$. For all simulations in the present work, the Courant number is chosen as 1 , and the convergence is judged by a residual decrease of at least three orders as well as a stable mass flow rate.

To check the reliability of the numerical methods mentioned above, a validation case based on experiment results from [16] is addressed in the following. Out of different experimental cases available in [16], a two-dimensional mixed-compression inlet model GK01 which has two stage external wedge compression and a straight cowl lip and isolator is selected due to its simple configuration as shown in Figure 3(a). The design Mach number of the inlet is hypersonic at 7 . The pressure distribution along the compression surface is extracted from our simulation to compare with their available experimental data, shown in Figure 3(b) where a nice agreement can be observed, which also promises the accuracy of the adopted numerical methods for hypersonic inlet flow.

3.2. Numerical Setups. Only half of the inlet model is used for simulation in consideration of its symmetric configuration. Structured grids based on different inlet geometries under 


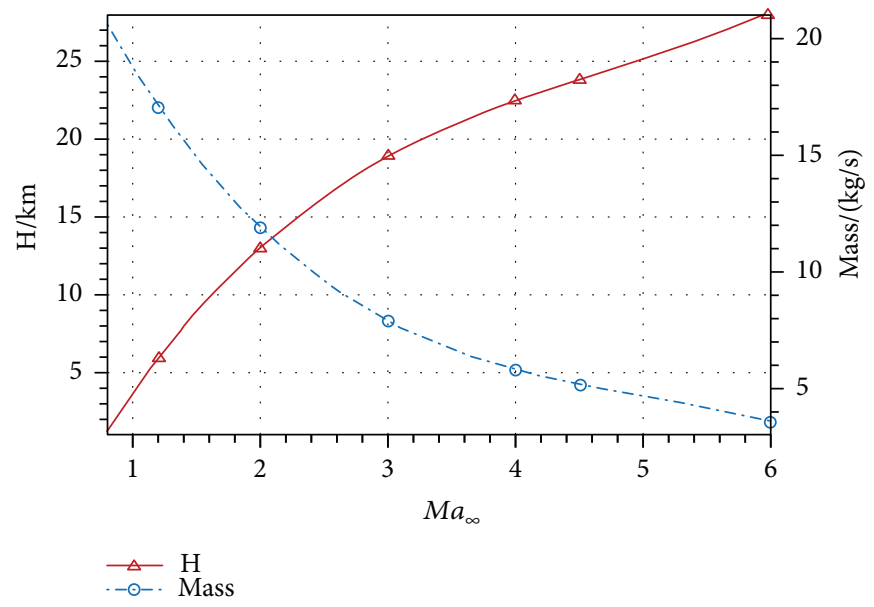

FIGURE 2: Working modes of the inlet.

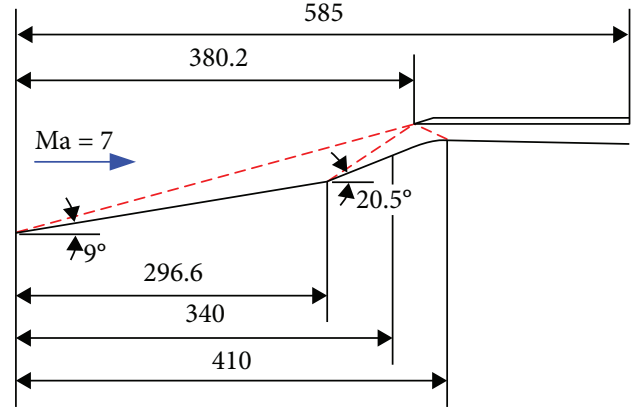

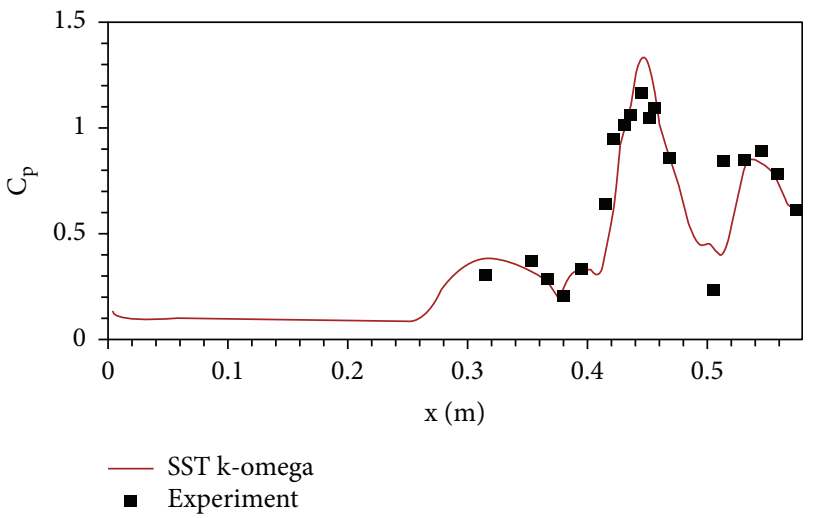

(b)

FIgure 3: (a) Configuration of the hypersonic inlet model GK01 extracted from [16] for validation. (b) Comparison of the pressure distribution along the compression surface between numerical simulation and experiment.

various working modes are built with Ansys ICEM 14.0@. The near-wall $y+$ is less than 10 to capture the surface boundary layer accurately. The pressure inlet boundary condition is set on the inflow surface, whereas the pressure outlet is set on the exit surface of the three ducts. The symmetry boundary condition is applied on the symmetry plane. A structured grid of the inlet under the turbojet mode with tri-ducts is shown in Figure 4, along with the abovementioned boundary conditions. Table 1 summarizes some basic numerical conditions for different working modes, in which the Reynolds number $(\mathrm{Re})$ is computed with a characteristic length of unity.

\section{Results and Discussion}

4.1. Single Duct. The inlet is mounted ventrally on the hypersonic vehicle in the present work, i.e., the cowl lip is in the bottom part, as indicated in Figures 5-11. The performance of the inlet with a single ramjet duct is analyzed at both design (Figure 5) and off-design (Figure 6) conditions. At cruise speed $M a_{\infty}=6$, the initial shock covers the entrance of the inlet thoroughly with a pressure ratio $\left(p / p_{0}\right)$ of around 2.4. The isobaric surfaces above the inlet leading edge and that under the cowl lip are due to the wall thickness which leads to additional external shocks. The initial shock hits the cowl lip and reflects inside the inlet with a pressure ratio $p / p_{0}=8$. The reflected shock further reflects near the inlet shoulder and also downstream inside the isolator. Obviously, the flow structure of the single-duct inlet under the design condition is as clear as desired. The performance of the inlet, which is mass averaged and summarized in Table 2, can be found quite well. The mass flow ratio, which is defined as the mass flow rate that really enters the duct over the mass flow rate that theoretically can be captured by the intake area, is nearly unity; whereas the total pressure recovery, which is defined as the total pressure at the end of the duct over the total pressure of the inflow, reaches 0.61 . The exit pressure ratio, which is defined as the exit static pressure over the inflow static pressure to evaluate the inlet compression ability, is over 20 .

To guarantee the reliability of the inlet system, the singleduct inlet must work properly at low Mach numbers. Figure 6 


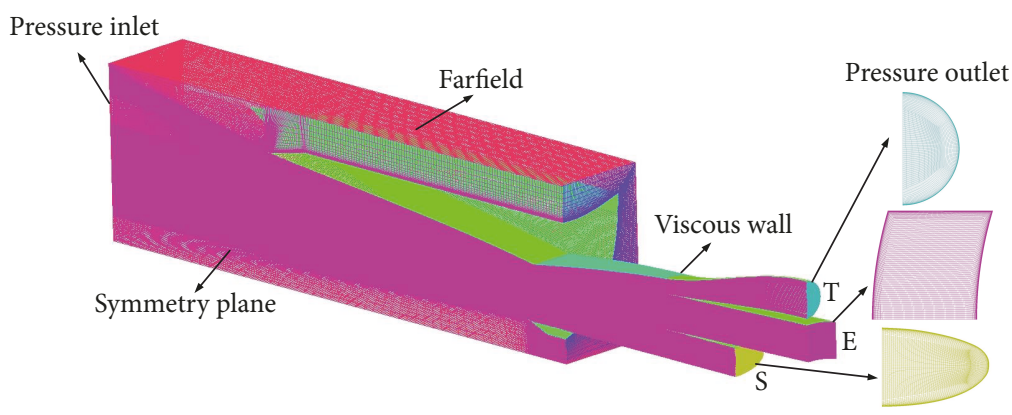

FIGURE 4: Structured grid for the tri-duct inlet.

TABLE 1: Summary of the flight conditions for the different working modes.

\begin{tabular}{lccccc}
\hline Case & $M a_{\infty}$ & $\begin{array}{c}\text { Density } \\
\left(\mathrm{kg} / \mathrm{m}^{3}\right)\end{array}$ & $\begin{array}{c}\text { Pressure } \\
(\mathrm{Pa})\end{array}$ & $\begin{array}{c}\mathrm{Re} \\
\left(\times 10^{6}\right)\end{array}$ & $\begin{array}{c}\text { Grid } \\
\left(\times 10^{6}\right)\end{array}$ \\
\hline $\begin{array}{l}\text { Single } \\
\text { duct }\end{array}$ & 6 & 0.025 & 1616.17 & 2.52 & 3.6 \\
\hline Dual & 4.5 & 0.046 & 2971.69 & 3.06 & \\
ducts & 4 & 0.064 & 4047.42 & 4.24 & 6.8 \\
\hline Tri-ducts & 2 & 0.112 & 6994.78 & 5.54 & \\
& 1.2 & 0.246 & 15327.56 & 8.11 & 8.6 \\
\hline
\end{tabular}

shows the isobaric flow structure of the inlet at the off-design condition $M a_{\infty}=4.5$. The initial shock angle increases and results in a leakage between the initial shock and the entrance of the inlet. The spilled mass flow occupies nearly 1/7 of the total captured mass flow at the current state. The highspeed air downstream the initial shock hits the cowl lip and generates a reflected shock with a pressure ratio of around 4.5. Further shock reflections can also be observed inside the inlet isolator. The total pressure recovery increases to 0.66 at $M a_{\infty}=4.5$ compared to 0.61 at the design condition due to decrease of the shock strength. Detailed performance of the inlet can be found in Table 2 .

4.2. Dual Ducts. When the operating Mach number decreases below 4 , the flap rotates outwards and consequently, the ejector duct is switched on. Figure 7 addresses the flow contour of the inlet with dual ducts at $M a_{\infty}=4$. The leakage between the initial shock and the entrance of the inlet is further enlarged compared to the above single-duct mode. The strength of the initial shock is decreased to a pressure ratio of 1.6. Shock reflections inside the inlet are quite obvious, as illustrated by the isobaric surfaces of $p / p_{0}=3.7$. A strong flow expansion just downstream the hinge of the rotational flap can be observed. Meanwhile, the cowl lip-reflected shock interacts with the boundary layer of the upper wall and forms a local separation bubble.

By further decreasing the inflow Mach number to 3, the strength of the initial shock is even decreased to $p / p_{0}=1.5$. The leakage between the initial shock and the entrance of the inlet is also increased to balance the mass flow that can be swallowed by the throat area of the inlet, leading to over $20 \%$ mass spillage. An obvious vortex region with low kinetic energy near the symmetry plane of the upper wall can be observed in Figure 8, which significantly weakens the inlet performance, e.g., the total pressure ratio of the ejector duct is $19 \%$ lower than that of the scramjet duct. Table 3 summarizes the overall performance of the dual-duct inlet, from which it can also be found that most of the captured flow enters the ejector duct due to its larger cross-section area.

Compared to the previous single-duct inlet, the throat area of the dual-duct inlet is twice larger, which guarantees a better startability. As mentioned in Section 2, the internal contraction ratio of the dual-duct inlet is nearly unity. Therefore, inlet compression can be treated as being accomplished fully externally. As we know that external compression inlets exhibit no starting difficulty, it is therefore a big advantage, especially under low Mach numbers, for the current inlet to work efficiently. Under the dual-duct mode, another important issue is that each of the dual ducts has to be noninternal contraction, i.e., the scramjet duct and the ejector duct must both be homolographic or expansion. This is even strictly necessary when the dual-duct inlet has to work properly at Mach number as low as only 2. In industrial applications, the throat area does not need to be fixed open during a wide working range, but can actually be adjusted to promise a certain compression ratio and ensure the startability of the inlet for different inflow Mach numbers. For instance, an intermediate state where the flap has been rotated to the middle of the ejector flow path is addressed in Figure 9. Obviously, compared to the fully open ejector duct in Figure 7, more air flows into the scramjet duct currently due to the same amount of the total captured air mass, i.e., the mass flow ratio of the scramjet duct increases from 0.32 to 0.45 during this mode transition period. Further detailed analysis on the control of the flap rotation needs to be accomplished in the near future.

4.3. Tri-Ducts. For inflow Mach number below 2 , the turbojet duct is switched on by further rotating the flap to a larger angle, which also indicates a stronger Prandtl-Meyer expansion around the hinge. The leakage between the initial shock and the inlet cowl lip is further enlarged, spilling around $40 \%$ of the captured mass flow. The strength of the initial shock is 


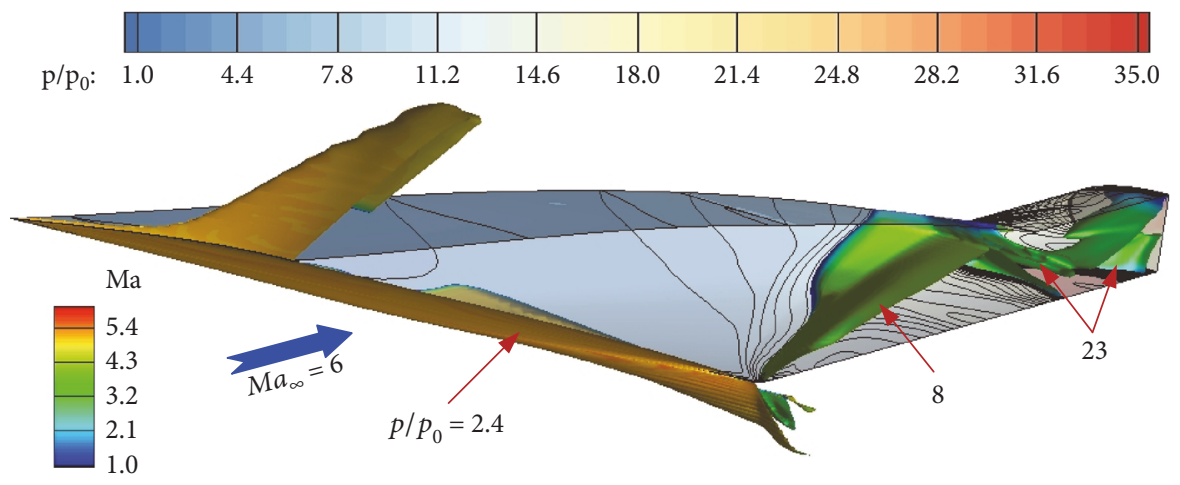

FIgURE 5: Flow contour of the inlet at $M a_{\infty}=6$. The surface wall is contoured by the pressure ratio $p / p_{0}$, whereas the three isobaric surfaces, respectively, $p / p_{0}=2.4,8$, and 23 , are contoured by the Mach number.

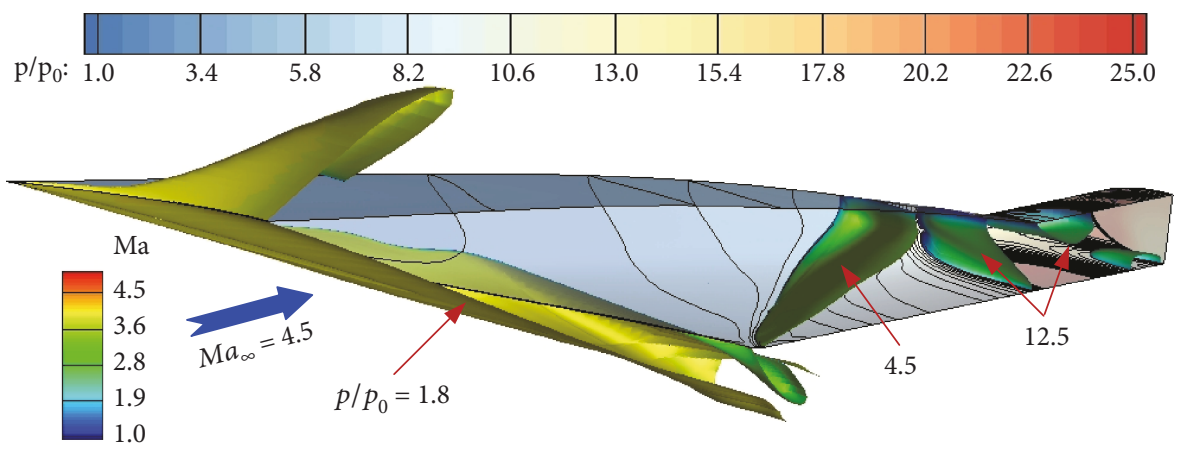

Figure 6: Flow contour of the inlet at $M a_{\infty}=4.5$. The surface wall is contoured by the pressure ratio $p / p_{0}$, whereas the three isobaric surfaces, respectively, $p / p_{0}=1.8,4.5$, and 12.5 , are contoured by the Mach number.

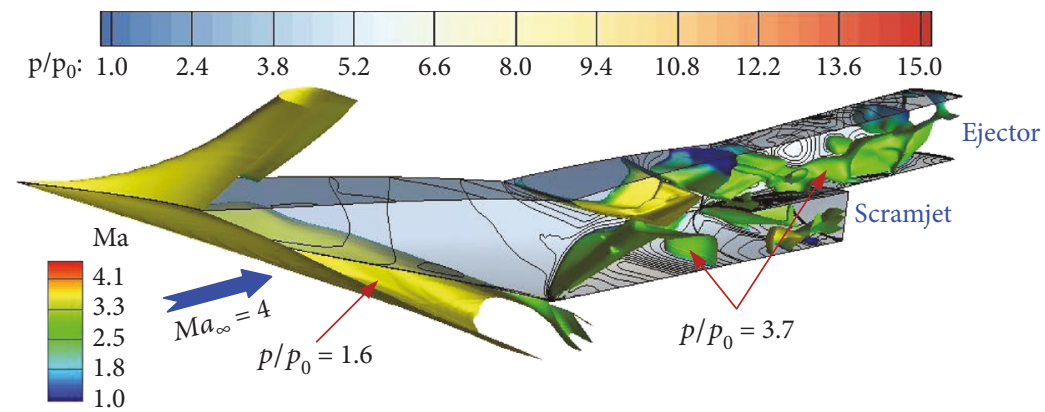

Figure 7: Flow contour of the inlet at $M a_{\infty}=4$. The surface wall is contoured by the pressure ratio $p / p_{0}$, whereas the two isobaric surfaces, respectively, $p / p_{0}=1.6$ and 3.7, are contoured by the Mach number.

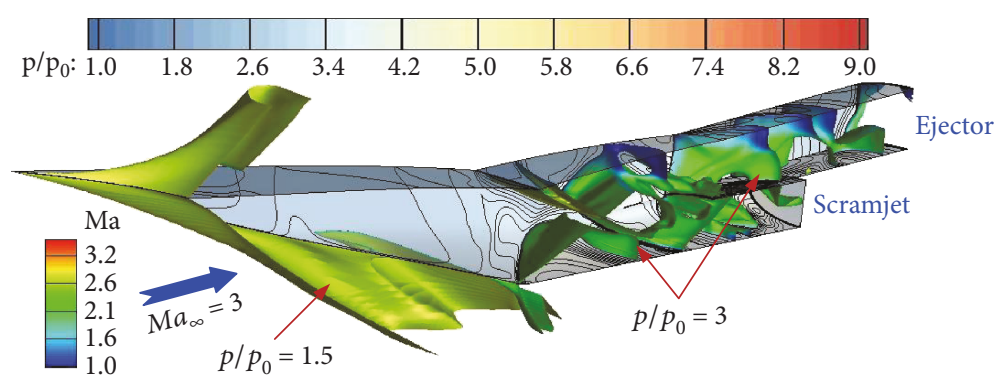

FIGURE 8: Flow contour of the inlet at $M a_{\infty}=3$. The surface wall is contoured by the pressure ratio $p / p_{0}$, whereas the two isobaric surfaces, respectively, $p / p_{0}=1.5$ and 3 , are contoured by the Mach number. 


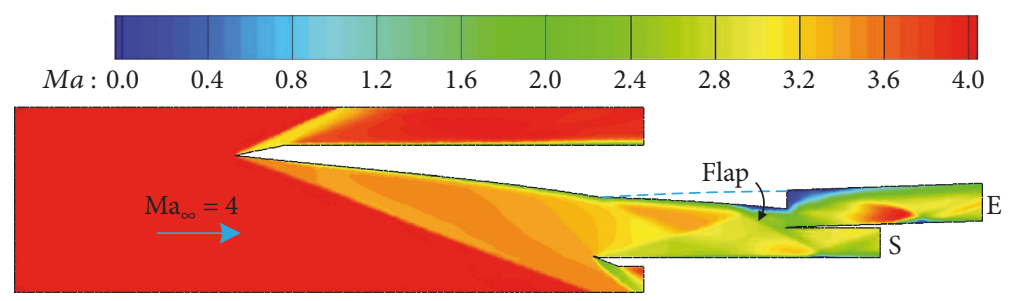

Figure 9: Flow contour of the inlet at $M a_{\infty}=4$ with an intermediate state where the flap rotates to the middle of the ejector flow path.

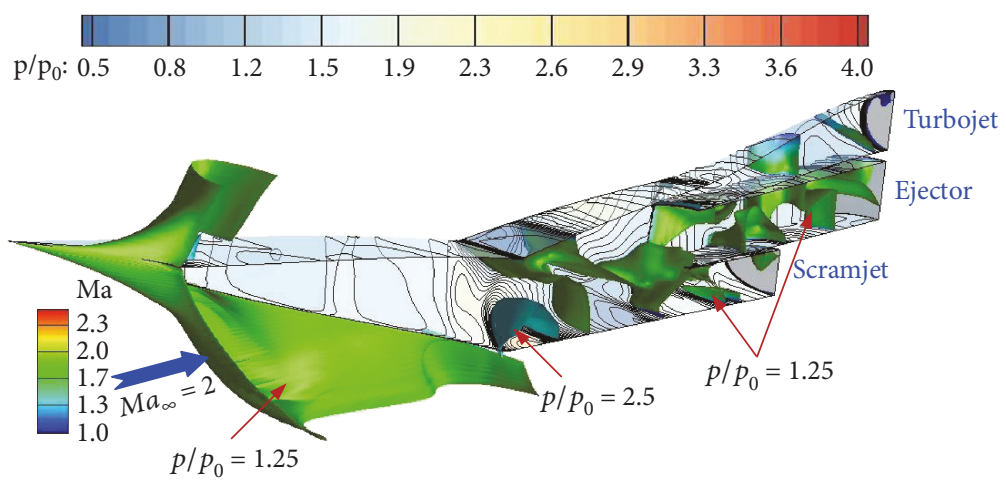

Figure 10: Flow contour of the inlet at $M a_{\infty}=2$. The surface wall is contoured by the pressure ratio $p / p_{0}$, whereas the two isobaric surfaces, respectively, $p / p_{0}=1.25$ and 2.5 , are contoured by the Mach number.

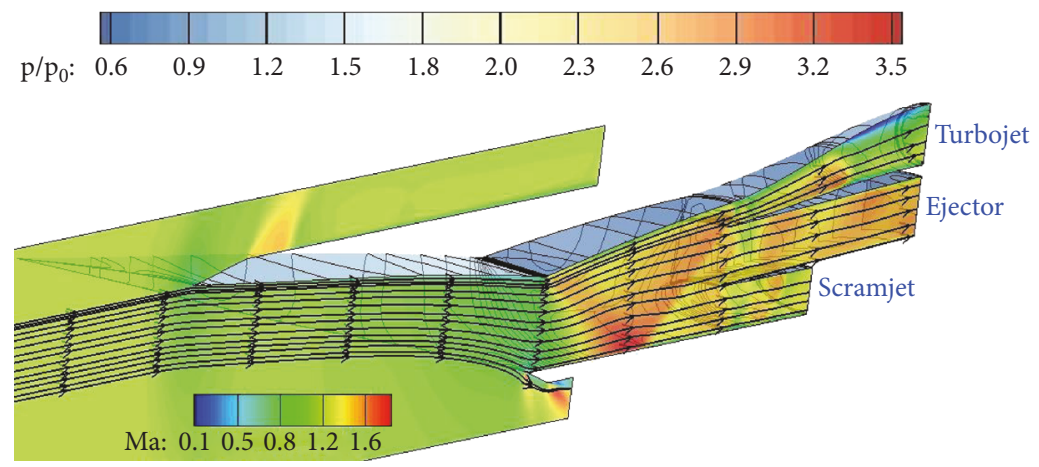

Figure 11: Flow contour of the inlet at $M a_{\infty}=1.2$. The surface wall is contoured by the pressure ratio $p / p_{0}$. The symmetry slice is contoured by the Mach number, accompanied with streamlines showing mass flow distribution into different paths.

TABLE 2: Mass-averaged performance of the single-duct inlet under both design and off-design conditions.

\begin{tabular}{lcccc}
\hline$M a_{\infty}$ & $\begin{array}{c}\text { Mass flow } \\
\text { ratio }\end{array}$ & $\begin{array}{c}\text { Total pressure } \\
\text { recovery }\end{array}$ & $\begin{array}{c}\text { Exit Mach } \\
\text { number }\end{array}$ & $\begin{array}{c}\text { Exit pressure } \\
\text { ratio }\end{array}$ \\
\hline 6 & 1 & 0.61 & 2.96 & 20.83 \\
4.5 & 0.88 & 0.66 & 2.09 & 18.75 \\
\hline
\end{tabular}

TABLE 3: Mass-averaged performance of the dual-duct inlet at $M a_{\infty}=4$ and 3 .

\begin{tabular}{cccccc}
\hline$M a_{\infty}$ & $\begin{array}{c}\text { Mass flow } \\
\text { ratio }\end{array}$ & $\begin{array}{c}\text { Total pressure } \\
\text { recovery }\end{array}$ & $\begin{array}{c}\text { Exit Mach } \\
\text { number }\end{array}$ & $\begin{array}{c}\text { Exit pressure } \\
\text { ratio }\end{array}$ \\
\hline \multirow{2}{*}{4} & $\mathrm{E}$ & 0.51 & 0.63 & 2.60 & 3.89 \\
& $\mathrm{~S}$ & 0.32 & 0.76 & 2.91 & 3.19 \\
\hline \multirow{3}{*}{3} & $\mathrm{E}$ & 0.40 & 0.65 & 1.97 & 2.74 \\
& $\mathrm{~S}$ & 0.34 & 0.84 & 2.06 & 3.59 \\
\hline
\end{tabular}


TABLE 4: Mass-averaged performance of the tri-duct inlet at $M a_{\infty}=2$ and 1.2.

\begin{tabular}{cccccc}
\hline$M a_{\infty}$ & $\begin{array}{c}\text { Mass flow } \\
\text { ratio }\end{array}$ & $\begin{array}{c}\text { Total pressure } \\
\text { recovery }\end{array}$ & $\begin{array}{c}\text { Exit Mach } \\
\text { number }\end{array}$ & $\begin{array}{c}\text { Exit } \\
\text { pressure } \\
\text { ratio }\end{array}$ \\
\hline 2 & $\mathrm{~T}$ & 0.06 & 0.48 & 0.56 & 2.93 \\
2 & $\mathrm{E}$ & 0.32 & 0.84 & 1.52 & 1.68 \\
& $\mathrm{~S}$ & 0.21 & 0.89 & 1.60 & 1.61 \\
\hline & $\mathrm{T}$ & 0.06 & 0.76 & 0.53 & 1.47 \\
1.2 & $\mathrm{E}$ & 0.25 & 0.90 & 0.84 & 1.38 \\
& $\mathrm{~S}$ & 0.15 & 0.89 & 1.16 & 0.92 \\
\hline
\end{tabular}

decreased to a pressure ratio of only 1.25 . Due to low air speed inside the inlet, shock reflections are weaker than those in the previous analysis. But obvious shock reflections with pressure ratio of 2.5 can still be observed in Figure 10 just downstream the cowl lip.

The tri-duct inlet is also simulated at the inflow Mach number 1.2, with a flow contour shown in Figure 11. Obvious expansion waves as well as reflections can be observed from the symmetry slice, with increased Mach numbers. And from the streamlines, a strong spillage exists (about 53\% of the captured mass flow, as can be summarized from Table 4). The mass distribution of the air that flows into the three ducts is about $1: 4: 2.5$, with respect to turbojet, ejector, and scramjet flow paths. This mass ratio does not strictly reflect the cross-section area of each duct, since the flow properties differ spatially due to wave reflections. The exit Mach number distribution of the turbojet flow path is provided in Figure 12 at both $M a_{\infty}=2$ and 1.2. As can be observed that the dominant flow structure is quite similar, with a high-speed region in the middle bottom while a low-speed range in the upper part. The difference however lies mostly on the size of the high-speed region, i.e., at Mach 2, it is bigger than that at Ma 1.2, as well as on the cause of the low-speed region $A$ and $B$ in Figure 12, i.e., at Mach 2, it is mainly due to the development of the thick boundary layer near the upper wall, whereas at Mach 1.2, it is more due to the upstream corner flow clipped by the upper and the side wall.

4.4. Discussion. To meet the requirement of three combined engines under a wide speed range and meanwhile keep robust startability and performance, we had to warily design the inlet. The mass flow ratio of the entire inlet and the mass distribution among different ducts are summarized for different modes in Figure 13(a). Obviously, with increasing Mach number, the total mass flow ratio $(\varphi)$ increases as well, from 0.46 at $M a_{\infty}=1.2$ to 1 at $M a_{\infty}=6$. This curve splits the figure into the upper and the lower parts, which indicate the spilled mass and the swallowed mass, respectively. The mass flow ratio for each specific duct also shows a tendency of increasing, e.g., $\varphi$ of the ejector duct keeps a nearly linear increase from 0.25 to 0.51 within the Mach range 1.2 and 4 .

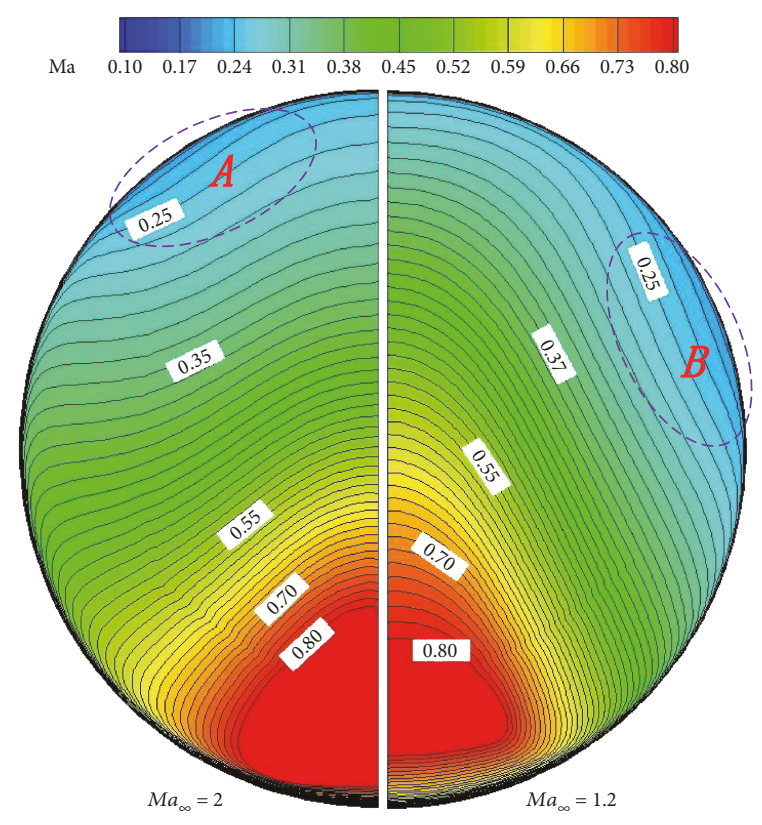

Figure 12: The exit Mach number distribution of the turbojet flow path at both $M a_{\infty}=2$ and 1.2.

The only exception is that the scramjet duct exhibits a slight decrease of $\varphi$ at $M a_{\infty}=4$ due to the strong flow deflection near the flap hinge caused by expansion waves, as can be observed in Figure 7. It can also be found from the mass distribution that the ejector duct always swallows the highest mass fraction among the three ducts due to its largest cross-section area. But in industrial applications, the mass requirement of each duct must be carefully provided according to the analysis of the entire propulsion system, especially from the consideration of thrust balance for combined cycle engine concepts.

The mass-averaged total pressure recovery of the three ducts is also summarized in Figure 13(b). With increasing Mach number, the total pressure recovery $(\sigma)$ decreases accordingly. At the cruise speed, the scramjet duct still obtain a high total pressure recovery of 0.61 . But $\sigma$ of the turbojet duct at low speeds is relatively weak, which is 0.76 at $M a_{\infty}=1.2$ and only 0.48 at $M a_{\infty}=2$. As we know that the vehicle in the speed range below Mach 2 mostly relies on the power of the turbine engine, such high total pressure loss is hence not sustainable for industrial applications. There will be two possible solutions. On one hand, the strong expansion near the hinge could be weakened to avoid local high Mach number. On the other hand, assuming a constant Mach number and area, the total pressure recovery is directly proportional to the flow mass, i.e., a higher total pressure recovery can be obtained by increasing the flow mass. But just as mentioned in the previous paragraph, determination of the flow mass and performance of each duct needs an overall analysis rather than a single-duct judgement. It is a rather complex systematical design for tri-combined inlet/engine concept in order to meet all the performance requirements, from the entire engine to each single duct. 


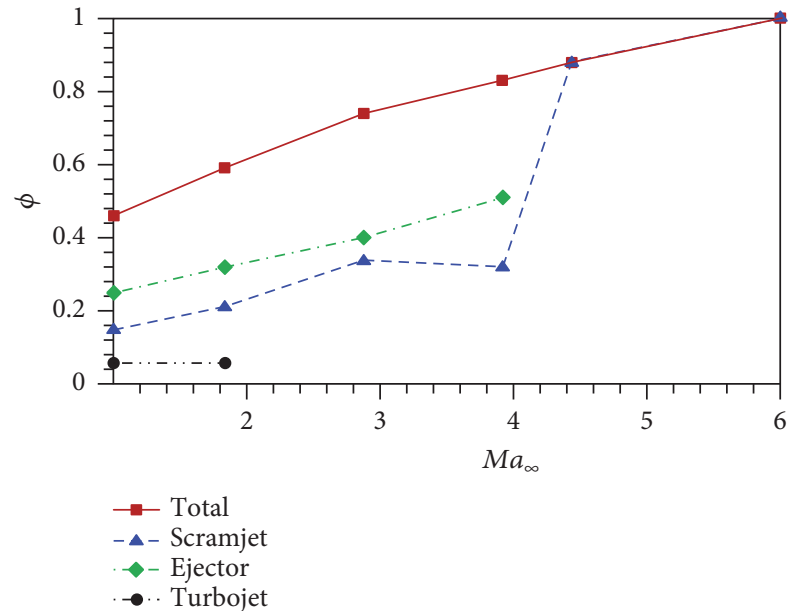

(a)

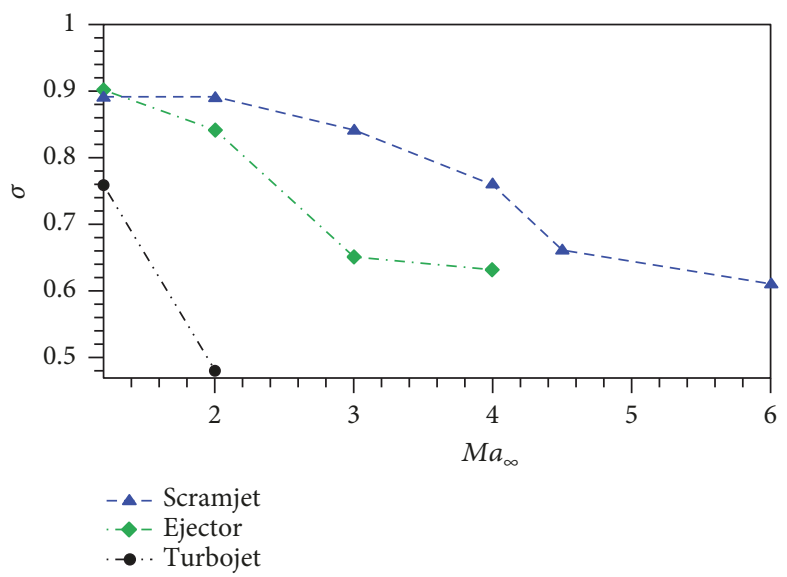

(b)

Figure 13: (a) Mass flow ratio of the inlet (with total and each single duct) at different Mach numbers. (b) Total pressure recovery of the inlet at different Mach numbers.

\section{Conclusions}

A three-dimensional tri-duct hypersonic inward-turning inlet has been designed for combined cycle engines in the present work, with only a single rotational flap on the compression side, which significantly simplifies the inlet structure and the flap control mechanism in a quite efficient way. The performance of the tri-duct inlet is analyzed based on three different working modes. Under the scramjet mode, only the high-speed duct is open, i.e., it works as a pure scramjet inlet which obtains a nearly unity mass flow ratio and a total pressure ratio of 0.61 at the cruise speed. At Mach 4.5, this single-duct inlet also exhibits nice startability and performance. For the dualduct mode, however, the biggest challenge lies on the inlet start in a wide speed range. The throat area is therefore warily determined, which is limited nearly identical to the exit area in order to guarantee the startability. For the tri-duct mode, over $40 \%$ of the captured mass flow has been spilled out of the inlet at Mach 2 due to the weak initial shock with a pressure ratio of only 1.25 . The mass distribution of the air is about $1: 4: 2.5$ into the three flow paths with respect to turbojet, ejector, and scramjet duct. We also addressed that the mass distribution among different flow paths of similar combined cycle inlets must be carefully determined to meet the requirement of the entire propulsion system, including thrust balance, startability, and performance. In the future, more efforts will be put on the mass distribution analysis as well as validation experiments of similar multiduct inlet.

\section{Data Availability}

The data used to support the findings of this study are available from the corresponding author upon request.

\section{Conflicts of Interest}

The authors declare that they have no conflicts of interest.

\section{Acknowledgments}

The authors thank the National Natural Foundation of China (No. 51606161), Fundamental Research Funds for the Central Universities (No. 20720170055), Soft Science Foundation of Fujian Province (No. 2017R0099), and Jiangsu Province Key Laboratory of Aerospace Power System for the financial support of this project.

\section{References}

[1] J. Steelant, "Sustained hypersonic flight in Europe: technology drivers for LAPCAT II," in 16th AIAA/DLR/DGLR International Space Planes and Hypersonic Systems and Technologies Conference, pp. 1-8, Bremen, Germany, October 2009, AIAA 2009-7240.

[2] J. Steelant, R. Varvill, S. Defoort, K. Hannemann, and M. Marini, "Achievements obtained for sustained hypersonic flight within the LAPCAT-II project," in 20th AIAA International Space Planes and Hypersonic Systems and Technologies Conference, pp. 1-56, Glasgow, Scotland, July 2015, AIAA 2015-3677.

[3] H. Kobayashi, H. Taguchi, T. Kojima, and T. Sato, "Performance analysis of Mach 5 hypersonic turbojet developed in JAXA," in 18th AIAA/3AF International Space Planes and Hypersonic Systems and Technologies Conference, pp. 1-9, Tours, France, September 2012, AIAA 2012-5839.

[4] M. J. Bulman and A. Siebenhaar, "Combined cycle propulsion: Aerojet innovations for practical hypersonic vehicles," in 17 th AIAA International Space Planes and Hypersonic Systems and Technologies Conference, pp. 1-11, San Francisco, CA, USA, April 2011, AIAA 2011-2397. 
[5] A. Siebenhaar and T. J. Bogar, "Integration and vehicle performance assessment of the Aerojet "TriJet" combined-cycle engine," in 16th AIAA/DLR/DGLR International Space Planes and Hypersonic Systems and Technologies Conference, pp. 1-9, Bremen, Germany, October 2009, AIAA 2009-7420.

[6] B. Wei, W. Ling, F. Luo, and Q. Gang, "Propulsion performance research and status of TRRE engine experiment," in 21st AIAA International Space Planes and Hypersonics Technologies Conference, pp. 1-12, Xiamen, China, March 2017, AIAA 2017-2351.

[7] Y. Hui, M. Jun, Y. Man, S. Zhu, W. Ling, and X. Cao, "Numerical simulation of variable-geometry inlet for TRRE combined cycle engine," in 21st AIAA International Space Planes and Hypersonics Technologies Conference, pp. 1-12, Xiamen, China, March 2017, AIAA 2017-2437.

[8] A. Kantrowitz and C. D. Donaldson, "Preliminary investigation of supersonic diffusers," Tech. Rep. NACA-WR-L-713, National Advisory Committee for Aeronautics, Langley Aeronautical Laboratory, Langley Field, VA, USA, 1945.

[9] C. J. Pan, C. G. Shi, Y. Q. Li, Y. C. You, and R. Q. Chen, "A new understanding of hypersonic inlets' startability criterion," Journal of Propulsion Technology, vol. 37, no. 11, pp. 20392047, 2016.

[10] Y. C. You and D. W. Liang, "Investigation of internal compression flowfield for internal waverider-derived inlet," Acta Aerodynamica Sinica, vol. 26, no. 2, pp. 203-207, 2008.

[11] J. L. Guo, G. P. Huang, Y. C. You, and D. W. Liang, "Study of internal compression flowfield for improving the outflow uniformity of internal waverider inlet," Journal of Astronautics, vol. 30, no. 5, pp. 1934-1940, 2009.

[12] C. X. Zhu, G. P. Huang, Y. C. You, and M. Zhou, "Performance comparison between internal waverider inlet and typical sidewall compression inlet," Journal of Propulsion Technology, vol. 32, no. 2, pp. 151-158, 2011.

[13] M. Zhou, G. Huang, C. Zhu, and Y. You, "Research on start ability of modular internal waverider inlet," Acta Aeronautica et Astronautica Sinica, vol. 33, no. 5, pp. 818-827, 2012.

[14] J. R. Davic and A. C. Midea, "Propulsion and aerodynamic analysis of the Beta II two-stage-to-orbit vehicle," in AIAA, Aircraft Design Systems Meeting, pp. 1-12, Hilton Head, SC, USA, August 1992, AIAA 92-4245.

[15] H. J. Zhang, X. G. Liu, R. W. Guo, and L. R. Xie, "Design of turbo diffuser for TBCC inlet based on characteristics of turbo mode," Journal of Aerospace Power, vol. 29, no. 1, pp. 181-191, 2014.

[16] J. Haberle and A. Gulhan, "Investigation of two-dimensional scramjet inlet flowfield at Mach 7," Journal of Propulsion and Power, vol. 24, no. 3, pp. 446-459, 2008. 


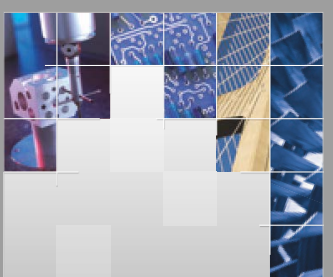

\section{Enfincering}
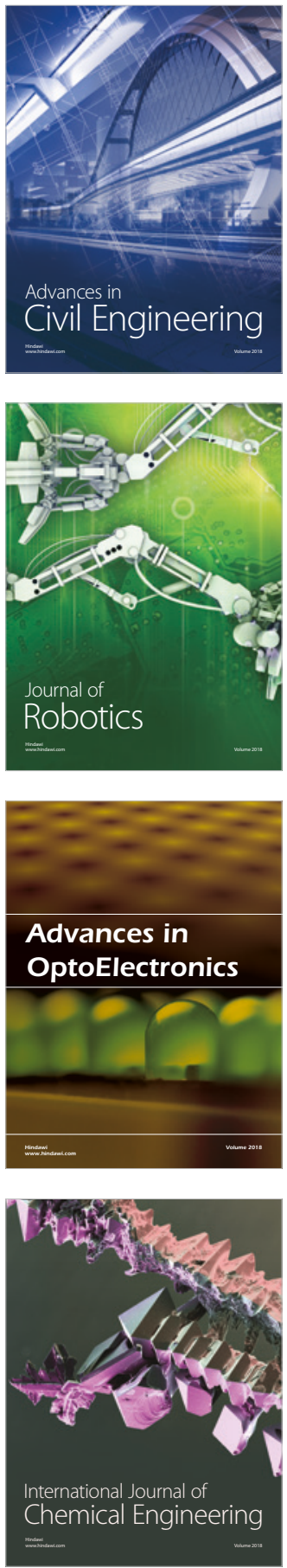

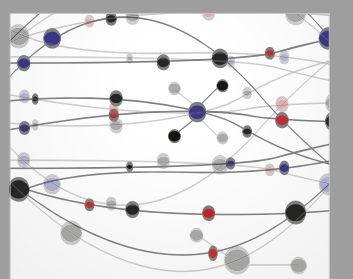

\section{Rotating \\ Machinery}

The Scientific World Journal

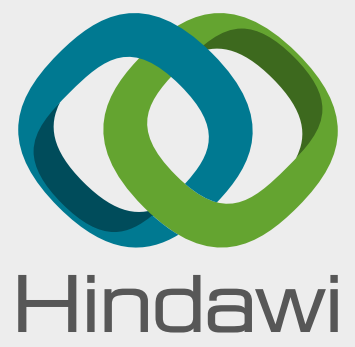

Submit your manuscripts at

www.hindawi.com
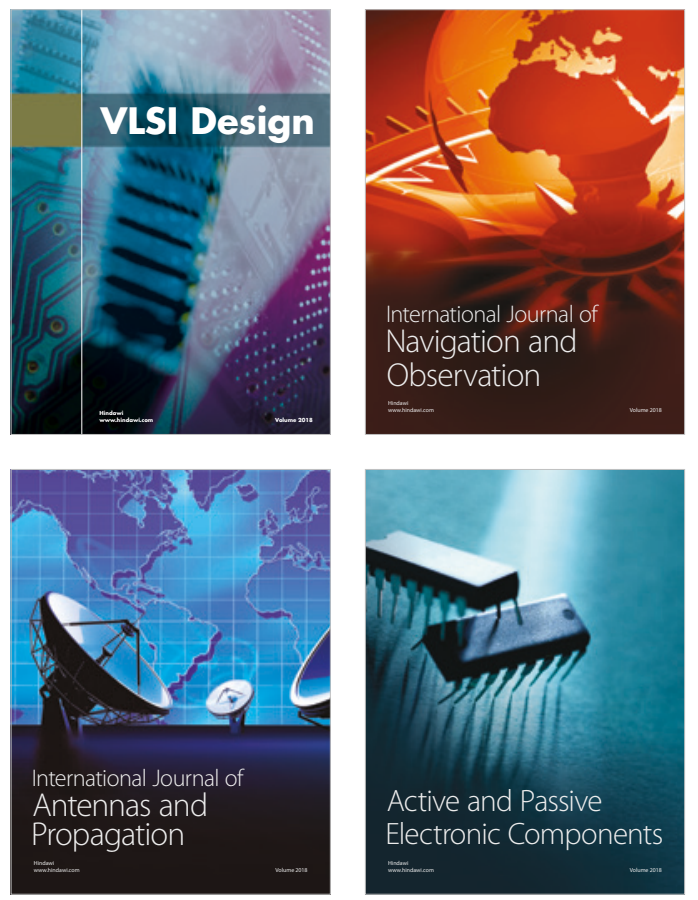
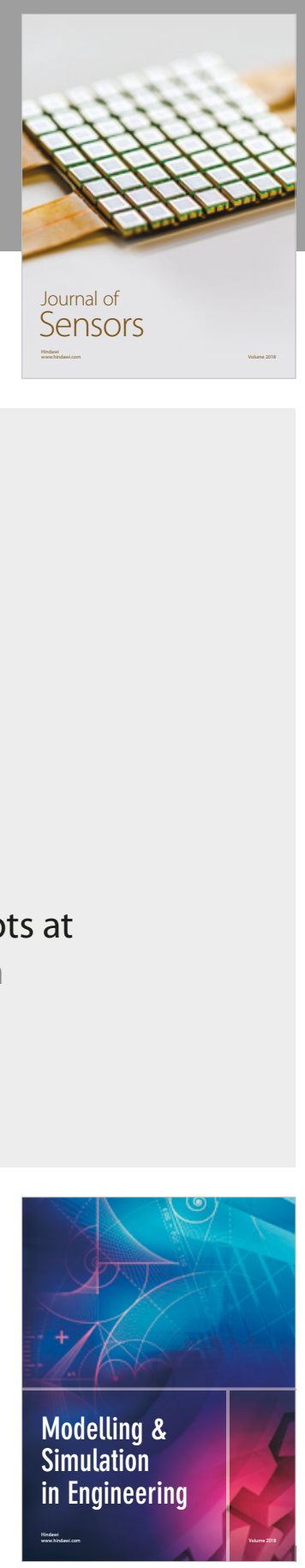

\section{Advances \\ Multimedia}
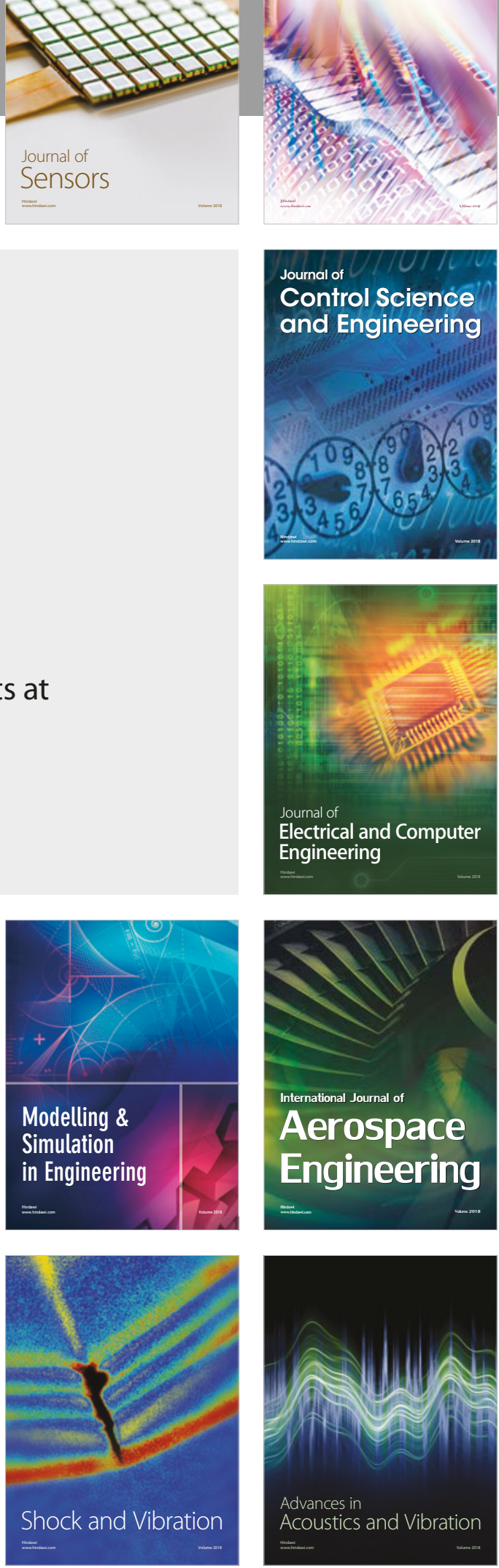